\title{
Efficacy of transanal tube placement after anterior resection for rectal cancer: a systematic review and meta-analysis
}

\author{
Shuanhu Wang ${ }^{*}$, Zongbing Zhang, Mulin Liu, Shiqing Li and Congqiao Jiang
}

\begin{abstract}
Background: Anastomotic leakage is a serious complication that can occur after anterior resection of the rectum. There is a question regarding whether the placement of a transanal tube can decrease the rate of anastomotic leakage. The aim of this systematic review and meta-analysis was to evaluate the efficacy of transanal tube placement after anterior resection.

Methods: We searched three major databases (PubMed, Embase, and the Cochrane Library) up until January 2015 for studies evaluating the benefit of transanal tubes after anterior resection for rectal cancer. The primary outcome measure was the rate of clinical anastomotic leakage. Secondary outcome was the rate of reoperation. Pooled risk ratios (RR) with $95 \%$ confidence intervals (Cl) were obtained using random effects models.

Results: One randomized controlled trial and three observational studies involving 909 patients met inclusion criteria. Clinical anastomotic leakage occurred in $3.49 \%$ (14 of 401) of patients with transanal tubes and $12.01 \%$ (61 of 508) of patients without transanal tubes. Meta-analysis of the studies showed a lower risk of anastomotic leakage (RR, 0.32; $95 \% \mathrm{Cl} 0.18-0.58$ ) and reoperation related to leakage (RR, 0.19; $95 \% \mathrm{Cl} 0.08-0.46)$ when the transanal tube was placed.

Conclusions: While studies are few and mostly observational, the data to date indicate that placement of a transanal tube decreases the rate of clinical anastomotic leakage and reoperation related to leakage. More studies are needed to confirm these findings.
\end{abstract}

Keywords: Rectal cancer, Transanal tube, Anastomotic leakage

\section{Background}

In 1908, William Ernest Miles introduced the basis of modern rectal cancer surgery in a study published in Lancet. As late as the past few decades, his abdominoperineal resection has been the gold standard of rectal cancer treatment. In 1948, CF Dixon proposed another technique, one that allowed for sphincter preservation [1]. With the popularization of the concept of total mesorectal excision (TME) and improvements in surgical instruments, low anterior resection has become more commonly performed than permanent stoma. With the increase of anus-preserving operations, anastomotic leakage has drawn the attention of surgeons.

\footnotetext{
* Correspondence: knight01030103@126.com

Department of Gastrointestinal surgery, The First Affiliated Hospital of Bengbu Medical College, Bengbu, Anhui Province, China
}

Anastomotic leakage is defined as a defect of the intestinal wall at the site of anastomosis (including suture and staple lines in neorectal reservoirs) leading to a communication between the intra- and extraluminal compartments [2]. Anastomotic leakage after anterior resection of the rectum can be serious. The overall frequency of this complication has been reported at $8.58 \%$ [3]. Patients suffering from anastomotic leakage not only remain hospitalized longer but also have a lower survival rate $[4,5]$. Low anastomosis and male gender are considered independent risk factors for symptomatic anastomotic leakage [6, 7]. For this reason, surgeons have explored ways of reducing the incidence of anastomotic leakage. Some systematic reviews and metaanalyses have indicated that proximal fecal diversion can reduce the rate of anastomotic leakage and reoperation 
related to leakage [8-11]. Proximal fecal diversion by loop ileostomy or colostomy requires another surgery to close the stoma. This increases hospital costs and the rate of stoma-related complications [12]. While some surgeons place a defunctioning transanal tube in an attempt to reduce anastomotic leakage [13], others believe that transanal tube placement is ineffective in preventing leakage [14]. Thus, although defunctioning transanal tube placement is widely used in anterior resection for rectal cancer, it remains unclear whether this measure is useful to patients. We conducted this systematic review and metaanalysis of available data to determine whether a transanal tube reduces postoperative complications in patients undergoing anterior resection for rectal cancer.

\section{Methods}

\section{Publication search}

The electronic databases Pubmed, Embase, and the Cochrane Library were searched by two authors (S.W. and Z.Z.) up till January 2015. The search strategy included the following keywords in various combinations: "transanal tube," "transanal drainage," "transanal drainage tube," "transanal catheter," "anterior resection," "rectal cancer," and "anastomotic leakage." Free text searches and MeSH searches were performed. Of the articles included here, references were read to identify any related articles. No language restrictions were applied.

The inclusion criteria were biopsy-proven rectal cancer before operation, laparotomy or laparoscopy, radical resection, use of stapler anastomosis, and comparison of anterior resection with a transanal tube to anterior resection without a transanal tube. The exclusion criteria were defunctioning stoma, defunctioning stoma and transanal tube placement at the same time, emergency operation, and palliative operation.

\section{Data extraction}

Two authors independently assessed all titles and abstracts for relevance (S.W. and S.L.). Disagreements were resolved through discussion. In cases where no consensus could be reached, a third specialist was consulted (C.J.). If a study covered both handsewn and stapler anastomosis, it was included only if a breakdown of data by level of anastomosis was available. Studies were excluded if all anterior resections (both curative and palliative) were included, without any breakdown by level of anastomosis.

Two outcome variables were evaluated: clinical anastomotic leakage (primary outcome) and reoperation related to leakage (secondary outcome). Clinical anastomotic leakage was defined as the presence of clinical symptoms such as peritonitis, fever, or septicemia combined with the occurrence of pelvic abscess, discharge of feces, pus, or gas from the drainage tube, and formation of a rectovaginal fistula $[15,16]$. Radiologically confirmed anastomotic leakage with no clinical signs was not included. When the required information could not be obtained from the article, e-mails were sent to the authors requesting it. If there was no reply from the author, the data were considered missing.

Two authors (S.W. and M.L.) assessed the quality of the included articles. The Jadad scoring system was used to assess the quality of RCT [17]. The quality of the observational studies was assessed using the NewcastleOttawa quality assessment scale [18].

\section{Statistical analysis}

Statistical analysis was performed using Review Manager (RevMan, version 5.3, The Nordic Cochrane Centre, the Cochrane Collaboration, Copenhagen, Denmark). Statistical heterogeneity was assessed using $I^{2}$ and $\chi^{2}$ statistics.

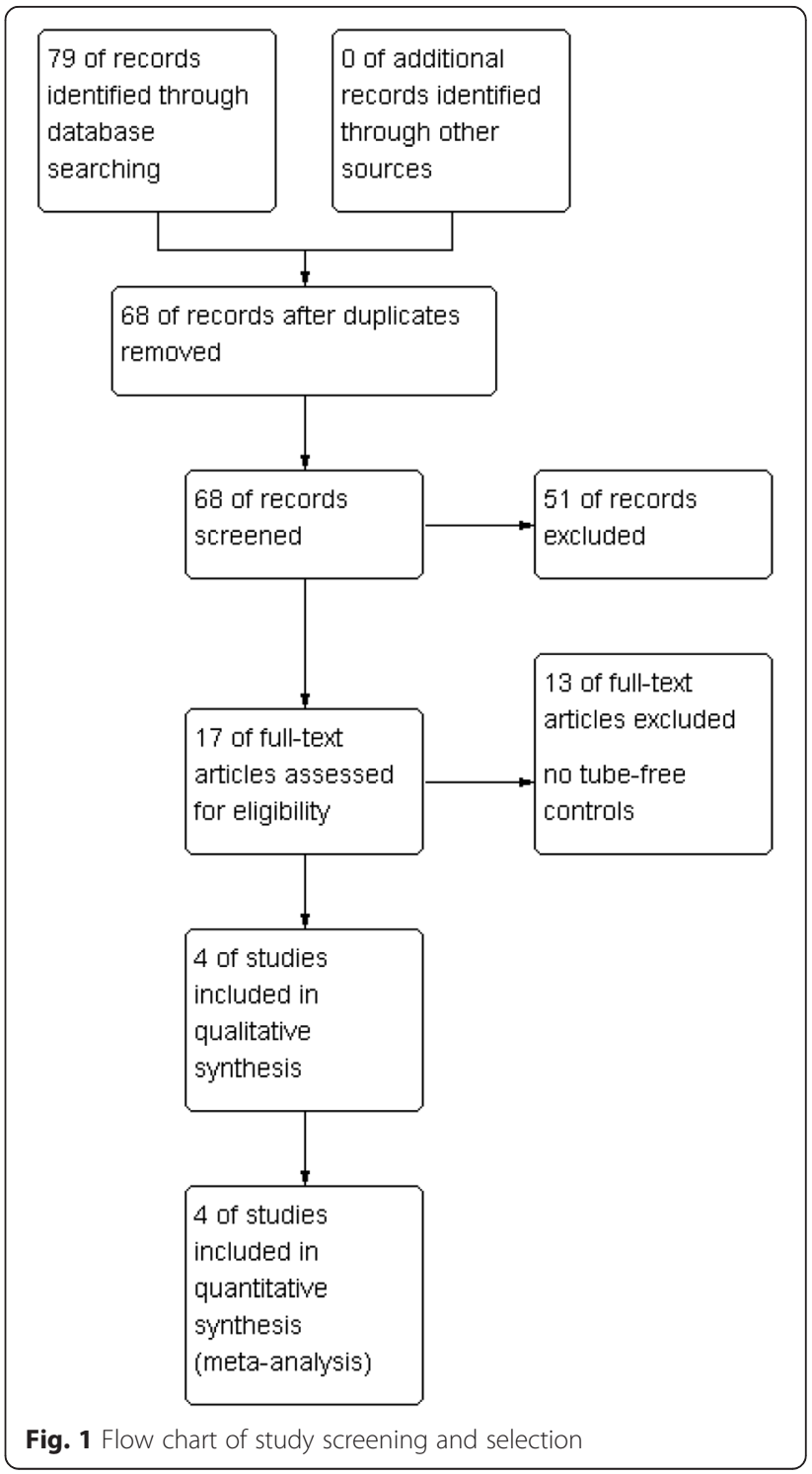


Table 1 Study characteristics

\begin{tabular}{|c|c|c|c|c|c|c|c|c|c|}
\hline \multirow[t]{2}{*}{ Study } & \multirow[t]{2}{*}{ Year } & \multirow[t]{2}{*}{ No. of patients } & \multirow[t]{2}{*}{ Type of operation } & \multicolumn{2}{|l|}{$n$} & \multicolumn{2}{|c|}{ Anastomotic leakage } & \multicolumn{2}{|c|}{ Reoperation } \\
\hline & & & & $\pi$ & $\mathrm{NTT}$ & $\pi$ & NTT & $\pi$ & NTT \\
\hline Xiao et al. [19] & 2011 & 370 & Laparotomy & 188 & 182 & $7(3.7)$ & $17(9.3)$ & $2(1.1)$ & $14(7.7)$ \\
\hline Nishigori et al. [20] & 2014 & 176 & Laparotomy and laparoscopy & 36 & 140 & $1(2.8)$ & $22(15.7)$ & $1(2.8)$ & $11(7.9)$ \\
\hline Hidaka et al. [21] & 2014 & 205 & Laparoscopy & 96 & 109 & $4(4.2)$ & $15(13.8)$ & $0(0)$ & $10(9.2)$ \\
\hline Zhao et al. [22] & 2013 & 158 & Laparotomy & 81 & 77 & $2(2.5)$ & $7(9.1)$ & $2(2.5)$ & $7(9.1)$ \\
\hline
\end{tabular}

Data are presented as $n(\%)$

$\pi$ transanal tube, NTT non-transanal tube

We estimated pooled risk ratio (RR) and $95 \%$ confidence interval (CI) for each outcome. Heterogeneity was considered significant if the $P$ value $\left(\chi^{2}\right)$ was $<0.1$ or $I^{2}$ was $>50 \%$. A random effects model was used even if no significant heterogeneity statistical heterogeneity was noted. This takes into account the low statistical power of tests of heterogeneity and the likelihood that clinical heterogeneity may exist even if statistical heterogeneity cannot be demonstrated. Sensitivity analysis was conducted by omitting each study one at a time in order to assess the influence of each single study on the overall risk estimate. Because of the limited number (below 10) of studies included in each analysis, publication bias was not assessed.

\section{Results}

The initial search retrieved 79 studies. After removal of 11 repeated studies, 68 articles remained. After reading the titles and abstracts of the studies, 51 studies were excluded because 1 was a systematic review (Poster Abstracts in Colorectal Disease) and another 50 were not relevant. Upon further review, 13 studies were excluded because the data regarded the placement of a transanal tube and nothing else. Finally, four articles were included (Fig. 1). The included studies were published between 2011 and 2014. Sample size of studies varied from 158 to 370 patients. One randomized controlled trial [19] and three observational studies [20-22] involved 909 patients, 401 of whom had a transanal tube and 508 did not. All studies reported clinical anastomotic leakage and reoperation related to leakage. Characteristics of the studies included are given in Table 1.

Three items (randomization, blinding, withdrawals, and dropouts) in the Jadad scoring system were used to assess the quality of the study. Eight elements in Newcastle-Ottawa quality assessment scale were used to assess patient population and selection, study comparability, follow-up, and outcome of interest. High-quality elements are awarded by adding a star, and then the stars are added up to compare the study quality. Assessment of the methodologic quality of studies using the three items in the Jadad scoring system for randomized trials and eight items in the Ottawa quality assessment scale for observational studies are shown in Table 2.

Four studies reported on clinical anastomotic leakage and reoperation. The pooled results from the three observational studies showed that transanal tubes was associated with a lower risk of both anastomotic leakage (pooled RR 0.32, $95 \%$ CI $0.18-0.58, P=0.0002$, Fig. 2) and reoperation $(0.19,95 \% \mathrm{CI} 0.08-0.46, P=0.0003$, Fig. 3). There was no significant heterogeneity for either outcome. The pooled RR for the three observational studies was similar to the RR in the randomized trial for both anastomotic leakage $(0.27,95 \%$ CI $0.12-0.60$ versus $0.40,95 \% \mathrm{CI} 0.17-0.94)$ and reoperation $(0.23$, $95 \%$ CI $0.07-0.70$ versus $0.14,95 \%$ CI $0.03-0.60$ ). Sensitivity analysis was performed by excluding each single study at a time. The effect on anastomotic leakage did not materially alter the pooled RR, which ranged from 0.27 (95\% CI $0.12-0.60, P=0.001)$ to 0.34 (95\% CI $0.19-0.63, P=0.0006)$. The pooled RR for reoperation ranged from $0.16(95 \% \mathrm{CI} 0.05-0.47, P=0.001)$ to 0.23 (95\% CI 0.07-0.70, $P=0.01$ ).

\section{Discussion}

Anastomotic leakage is a serious complication following surgery for rectal cancer. With the development of surgical instruments and surgical techniques, sphincter-

Table 2 Jadad score and Newcastle-Ottawa quality assessment scale

\begin{tabular}{llllll}
\hline Study & Jadad score (0-5) & Newcastle-Ottawa quality assessment scale cohort studies & \\
\hline Xiao et al. [19] & & Selection (0-4) & Comparability (0-2) & Outcome (0-3) & $* * *$ \\
Nishigori et al. [20] & - & $* * * *$ & $* *$ & $* * *$ & Total (0-9) \\
Hidaka et al. [21] & - & $* * * *$ & $* * *$ & $*$ \\
Zhao et al. [22] & - & $* * * * * * *$ & $*$ & 9 \\
\hline
\end{tabular}

There is one star for each point, a study can be given a maximum of nine stars 


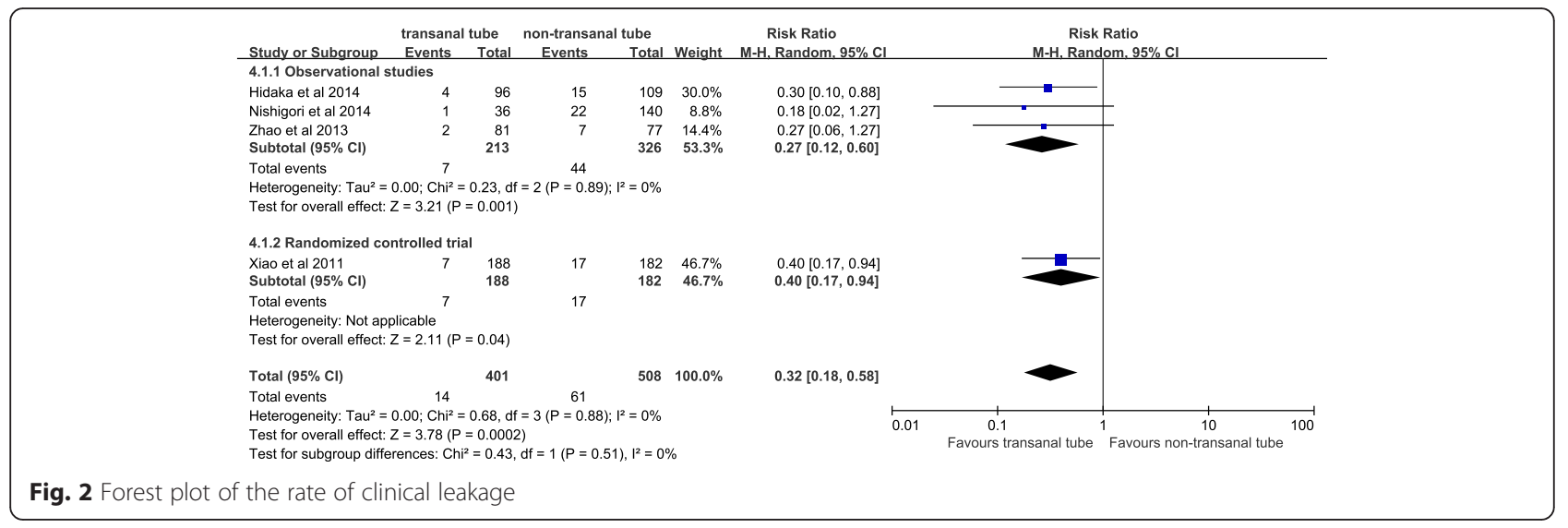

preserving procedures have become more prevalent [23]. However, the risk of anastomotic leakage is increasing $[24,25]$, and placement of a transanal tube for its prevention is controversial.

The present meta-analysis was conducted to evaluate existing data to help clarify the role of transanal tube placement in the prevention of anastomotic leakage and reoperation. Results of both the meta-analysis of the three observational studies and the one randomized trials indicate that placement of a transanal tube significantly decreases the risk of leakage and reoperation. While the mechanism of action of the transanal tube is unclear, it may be related to reduction in endoluminal pressure in the anastomotic portion of the intestine which may be an important factor in anastomotic leakage [26]. This is supported by the observation that rectal resting pressure was lower in the transanal tube group than in the tube-free group in one study [19]. The transanal tube may also directly drainage on the proximal side of the anastomosis [27, 28]. If anastomotic leakage occurs, a large amount of stool will leak to the peritoneal cavity in the tube-free group. Reoperation for anastomotic leakage will be inevitable. The rate of reoperation for anastomotic leakage was $8.3 \%$ (42 of 508) in the tube-free group. In contrast, stool could be drained from the rectum through the transanal tube. A small amount of stool might leak to the peritoneal cavity resulting in localized peritonitis. The localized peritonitis was cured conservatively by the placement of abdominal drainage tube. So the rate of reoperation for anastomotic leakage was only $1.3 \%$ (5 of 401) in the tube group.

These results are similar to those published in an earlier meta-analysis by Shigeta and co-workers [29]. However, that study was published only in a poster abstract. No further details were made available. The purpose of the present article is to fill this gap.

This meta-analysis followed clear methodology with clearly predefined inclusion and exclusion criteria, outcome measures, study quality appraisal, and statistical methods a priori. However, there are limitations that should be considered. First, there was only one RCT and three observational studies available for inclusion. Second, among the included studies, some patients underwent laparotomy and others underwent laparoscopy. But the rate of anastomotic leakage was not significant differences between laparotomy and laparoscopy group [30, 31]. The outer diameters of the transanal tube also varied from 24 to $28 \mathrm{Fr}$. These differences constitute

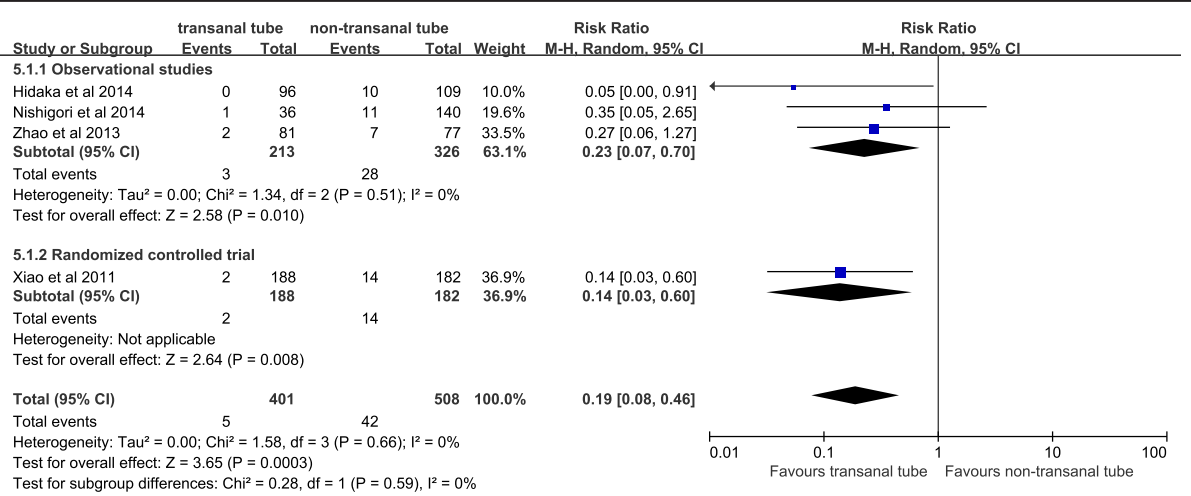

Fig. 3 Forest plot of reoperation rate 
clinical heterogeneity even though statistical heterogeneity was not demonstrated. Finally, the sample size of all studies was relatively small. However, the sensitivity of the analysis indicated that the results were robust.

Although transanal tube may reduce the risk of anastomotic leakage and reoperation, its placement increases patients' discomfort and inconvenience. There have also been reports of tubes perforating bowel especially in the region anterior to the sacrum [20]. However, compared with the reoperations required for anastomotic leakage in the absence of a transanal tube, complications associated with a transanal tube are relatively minor.

\section{Conclusions}

This systematic review and meta-analysis indicates that placement of transanal tubes after anterior resection reduces the risk of anastomotic leakage and reoperation. However, the studies are few and mostly observational. A well-powered, multicenter, randomized, controlled trial is needed to confirm these findings. If confirmed, the use of this intervention will improve outcomes and reduce complications in patients undergoing anterior resection.

\section{Abbreviations}

NTT: non-transanal tube; TME: total mesorectal excision; TT: transanal tube.

\section{Competing interests}

The authors declare that they have no competing interests.

\section{Authors' contributions}

S.W. conceived the study, extracted and analyzed the data, and drafted the manuscript. Z.Z. collected the data and helped to draft the manuscript. S.L. extracted the data. M.L. analyzed the data. C.J. participated in the study design. All authors read and approved the final manuscript.

\section{Acknowledgements}

The authors thank LetPub (www.letpub.com) for its linguistic assistance during the preparation of this manuscript.

Received: 13 July 2015 Accepted: 24 March 2016

Published online: 31 March 2016

\section{References}

1. Dixon CF. Anterior resection for malignant lesions of the upper part of the rectum and lower part of the sigmoid. Ann Surg. 1948;128(3):425-42.

2. Rahbari NN, Weitz J, Hohenberger W, Heald RJ, Moran B, Ulrich A, et al. Definition and grading of anastomotic leakage following anterior resection of the rectum: a proposal by the International Study Group of Rectal Cancer. Surgery. 2010;147(3):339-51. doi:10.1016/j.surg.2009.10.012.

3. Cong ZJ, Hu LH, Bian ZQ, Ye GY, Yu MH, Gao YH, et al. Systematic review of anastomotic leakage rate according to an international grading system following anterior resection for rectal cancer. PLoS One. 2013;8(9), e75519. doi:10.1371/journal.pone.0075519

4. Kulu Y, Tarantio I, Warschkow R, Kny S, Schneider M, Schmied BM, et al. Anastomotic leakage is associated with impaired overall and disease-free survival after curative rectal cancer resection: a propensity score analysis. Ann Surg Oncol. 2015:22(6):2059-67. doi:10.1245/s10434-014-4187-3.

5. Law WL, Choi HK, Lee YM, Ho JW, Seto CL. Anastomotic leakage is associated with poor long-term outcome in patients after curative colorectal resection for malignancy. J Gastrointest Surg. 2007;11(1):8-15. doi:10.1007/s11605-006-0049-z

6. Kang CY, Halabi WJ, Chaudhry OO, Nguyen V, Pigazzi A, Carmichael JC, et al. Risk factors for anastomotic leakage after anterior resection for rectal cancer. JAMA Surg. 2013;148(1):65-71. doi:10.1001/2013.jamasurg.2.
7. Matthiessen P, Hallbook O, Andersson M, Rutegard J, Sjodahl R. Risk factors for anastomotic leakage after anterior resection of the rectum. Colorectal Dis. 2004;6(6):462-9. doi:10.1111/j.1463-1318.2004.00657.x.

8. Chen J, Wang DR, Yu HF, Zhao ZK, Wang LH, Li YK. Defunctioning stoma in low anterior resection for rectal cancer: a meta-analysis of five recent studies. Hepatogastroenterology. 2012;59(118):1828-31. doi:10.5754/hge11786.

9. Gu WL, Wu SW. Meta-analysis of defunctioning stoma in low anterior resection with total mesorectal excision for rectal cancer: evidence based on thirteen studies. World J Surg Oncol. 2015;13:9. doi:10.1186/ s12957-014-0417-1.

10. Huser N, Michalski CW, Erkan M, Schuster T, Rosenberg R, Kleeff J, et al. Systematic review and meta-analysis of the role of defunctioning stoma in low rectal cancer surgery. Ann Surg. 2008;248(1):52-60. doi:10.1097/SLA. 0b013e318176bf65.

11. Tan WS, Tang CL, Shi L, Eu KW. Meta-analysis of defunctioning stomas in low anterior resection for rectal cancer. Br J Surg. 2009;96(5):462-72. doi:10.1002/bjs.6594.

12. Thoker M, Wani I, Parray FQ, Khan N, Mir SA, Thoker P. Role of diversion ileostomy in low rectal cancer: a randomized controlled trial. Int J Surg. 2014;12(9):945-51. doi:10.1016/j.jiju.2014.07.012.

13. Patrascu T, Doran H, Musat O. Protective transanal tube in colo-rectal anastomosis. Chirurgia (Bucur). 2004;99(1):75-8.

14. Cong ZJ, Fu CG, Wang HT, Liu LJ, Zhang W, Wang H. Influencing factors of symptomatic anastomotic leakage after anterior resection of the rectum for cancer. World J Surg. 2009;33(6):1292-7. doi:10.1007/s00268-009-0008-4

15. Eckmann C, Kujath P, Schiedeck TH, Shekarriz H, Bruch HP. Anastomotic leakage following low anterior resection: results of a standardized diagnostic and therapeutic approach. Int J Colorectal Dis. 2004;19(2):128-33. doi:10.1007/s00384-003-0498-8

16. Matthiessen P, Hallbook O, Rutegard J, Simert G, Sjodahl R. Defunctioning stoma reduces symptomatic anastomotic leakage after low anterior resection of the rectum for cancer: a randomized multicenter trial. Ann Surg. 2007;246(2):207-14. doi:10.1097/SLA.0b013e3180603024.

17. Jadad AR, Moore RA, Carroll D, Jenkinson C, Reynolds DJ, Gavaghan DJ, et al. Assessing the quality of reports of randomized clinical trials: is blinding necessary? Control Clin Trials. 1996;17(1):1-12.

18. Lo CK, Mertz D, Loeb M. Newcastle-Ottawa Scale: comparing reviewers' to authors' assessments. BMC Med Res Methodol. 2014;14 45. doi:10.1186/1471-2288-14-45.

19. Xiao L, Zhang WB, Jiang PC, Bu XF, Yan Q, Li H, et al. Can transanal tube placement after anterior resection for rectal carcinoma reduce anastomotic leakage rate? A single-institution prospective randomized study. World J Surg. 2011;35(6):1367-77. doi:10.1007/s00268-011-1053-3.

20. Nishigori $H$, Ito $M$, Nishizawa $Y$, Nishizawa $Y$, Kobayashi A, Sugito $M$, et al. Effectiveness of a transanal tube for the prevention of anastomotic leakage after rectal cancer surgery. World J Surg. 2014;38(7):1843-51. doi:10.1007/ s00268-013-2428-4.

21. Hidaka E, Ishida F, Mukai S, Nakahara K, Takayanagi D, Maeda C, et al. Efficacy of transanal tube for prevention of anastomotic leakage following laparoscopic low anterior resection for rectal cancers: a retrospective cohort study in a single institution. Surg Endosc. 2015;29(4):863-7. doi:10.1007/ s00464-014-3740-2.

22. Zhao WT, Hu FL, Li YY, Li HJ, Luo WM, Sun F. Use of a transanal drainage tube for prevention of anastomotic leakage and bleeding after anterior resection for rectal cancer. World J Surg. 2013;37(1):227-32. doi:10.1007/ s00268-012-1812-9.

23. Bordeianou L, Maguire LH, Alavi K, Sudan R, Wise PE, Kaiser AM. Sphincter-sparing surgery in patients with low-lying rectal cancer: techniques, oncologic outcomes, and functional results. J Gastrointest Surg. 2014;18(7):1358-72. doi:10.1007/s11605-014-2528-y.

24. Moran BJ. Predicting the risk and diminishing the consequences of anastomotic leakage after anterior resection for rectal cancer. Acta Chir lugosl. 2010;57(3):47-50.

25. Yang $L$, Huang XE, Zhou JN. Risk assessment on anastomotic leakage after rectal cancer surgery: an analysis of 753 patients. Asian Pac J Cancer Prev. 2013;14(7):4447-53.

26. Guenaga KF, Lustosa SA, Saad SS, Saconato $H$, Matos D. Uleostomy or colostomy for temporary decompression of colorectal anastomosis. Cochrane Database Syst Rev. 2007;1, CD004647. doi:10.1002/14651858. CD004647.pub2. 
27. Montemurro S, De Luca R, Caliandro C, Ruggieri E, Rucci A, Sciscio V, et al. Transanal tube NO COIL(R) after rectal cancer proctectomy. The "G. Paolo II" Cancer Centre experience. Tumori. 2012;98(5):607-14. doi:10.1700/1190.13202.

28. Montemurro S, Caliandro C, Ruggeri E, Rucci A, Sciscio V. Endoluminal pressure: risk factor for anastomotic dehiscence in rectal carcinoma. Preliminary results. Chir Ital. 2001;53(4):529-36.

29. Shigeta K, Baba H, Yamafuji K, Kubochi K. A meta-analysis of use of transanal tube to prevent anastomotic leakage after anterior resection for rectal cancer. Colorectal Disease. 2014;16:87.

30. Zhao JK, Chen NZ, Zheng JB, He S, Sun XJ. Laparoscopic versus open surgery for rectal cancer: results of a systematic review and meta-analysis on clinical efficacy. Mol Clin Oncol. 2014;2(6):1097-102. doi:10.3892/mco.2014.345

31. Rickert A, Herrle F, Doyon F, Post S, Kienle P. Influence of conversion on the perioperative and oncologic outcomes of laparoscopic resection for rectal cancer compared with primarily open resection. Surg Endosc. 2013;27(12): 4675-83. doi:10.1007/s00464-013-3108-z.

Submit your next manuscript to BioMed Central and we will help you at every step:

- We accept pre-submission inquiries

- Our selector tool helps you to find the most relevant journal

- We provide round the clock customer support

- Convenient online submission

- Thorough peer review

- Inclusion in PubMed and all major indexing services

- Maximum visibility for your research

Submit your manuscript at www.biomedcentral.com/submit
Biomed Central 